\title{
Impact of the sea surface temperature forcing on hindcasts of Madden-Julian Oscillation events using the ECMWF model
}

\author{
E. de Boisséson ${ }^{1,2}$, M. A. Balmaseda ${ }^{1}$, F. Vitart ${ }^{1}$, and K. Mogensen ${ }^{1}$ \\ ${ }^{1}$ European Centre for Medium Range Forecast, Shinfield Park, RG2 9AX, Reading, UK \\ ${ }^{2}$ CNRM/GAME, URA1357, 42 avenue Gaspard Coriolis, 31057, Toulouse, France \\ Correspondence to: E. de Boisséson (eric.boisseson@ecmwf.int)
}

Received: 29 June 2012 - Published in Ocean Sci. Discuss.: 23 July 2012

Revised: 31 October 2012 - Accepted: 13 November 2012 - Published: 11 December 2012

\begin{abstract}
This paper explores the sensitivity of hindcasts of the Madden Julian Oscillation (MJO) to the use of different sea surface temperture (SST) products as lower boundary conditions in the European Centre for Medium-range Weather Forecasts (ECMWF) atmospheric model. Three sets of monthly hindcast experiments are conducted, starting from initial conditions from the ERA interim reanalysis. First, as a reference, the atmosphere is forced by the SST used to produce ERA interim. In the second and third experiments, the SST is switched to the OSTIA (Operational Sea Surface Temperature and Sea-Ice Analysis) and the AVHRRonly (Advanced Very High Resolution Radiometer) reanalyses, respectively. Tests on the temporal resolution of the SST show that monthly fields are not optimal, while weekly and daily resolutions provide similar MJO scores. When using either OSTIA or AVHRR, the propagation of the MJO is degraded and the resulting scores are lower than in the reference experiment. Further experiments show that this loss of skill cannot be attributed to either the difference in mean state or temporal variability between the SST products. Additional diagnostics show that the phase relationship between either OSTIA or AVHRR SST and the MJO convection is distorted with respect to satellite observations and the ERA interim reanalysis. This distortion is expected to impact the MJO hindcasts, leading to a relative loss of forecast skill. A realistic representation of ocean-atmosphere interactions is thus needed for MJO hindcasts, but not all SST products though accurate for other purposes - fulfill this requirement.
\end{abstract}

\section{Introduction}

The Madden-Julian Oscillation (MJO) is the major mode of intraseasonal variability in the tropical atmosphere (Zhang, 2005). It is characterized by an eastward propagation of regions of both enhanced and suppressed convection, mainly observed over the Indian and the Pacific Oceans with a periodicity of about 30-70 days. The MJO is known to influence the Asian (e.g. Murakami, 1976; Yasunari, 1979) and Australian monsoons (Hendon and Liebmann , 1990), the evolution of El Nino events (e.g. Kessler and McPhaden, 1995) and the weather regimes over the North Atlantic European region in winter (Cassou, 2008; Vitart and Molteni, 2010). The simulation and the prediction of such intraseasonal and seasonal weather regimes need an accurate representation of the MJO in General Circulation Models (GCM). While simulating the MJO used to be difficult in terms of propagation (Slingo et al., 1996) and of intensity of the intraseasonal variability (Lin et al., 2006), these aspects are largely improved in new-generation models (Lin et al., 2008; Vitart and Molteni, 2010). Because of its importance for the predictability at intraseasonal and seasonal time scales, the MJO is one of the main benchmarks for the skill of extended-range forecast systems.

Air-sea interactions associated with the MJO are known to drive sea surface temperature (SST) perturbations that may feedback to the atmospheric dynamics and influence the MJO signal (Hendon, 2005). Krishnamurti et al. (1998) observed, from the FGGE (First GARP Global Experiment) data, an instraseasonal signal of SST in the Indian and the western Pacific Oceans. This signal had a temporal phasing with surface westerly winds indicative of an ocean forced by 
the atmosphere. The air-sea flux and SST data provided by the $1.45^{\circ} \mathrm{S}-156^{\circ} \mathrm{E}$ mooring of the TOGA-COARE (Tropical Ocean Global Atmosphere Coupled Ocean Atmosphere Response Experiment) program during the winter 1992-1993 (Anderson et al., 1998) clearly showed the response of SST to MJO surface fluxes. Warm SST anomalies followed the suppressed phase of the MJO, while cold SST anomalies followed the convective phase of the MJO (Shinoda et al., 1998). Using satellite and reanalysis data, Woolnough et al. (2000) confirmed that the SST intraseasonal variability is driven by the atmosphere via air-sea interactions.

The SST anomalies associated to the MJO are expected to influence the latent and sensible heat fluxes and thus affect the MJO signal. Both works from Woolnough et al. (2007) and Vitart et al. (2007) introduced ocean-atmosphere coupling in the Integrated Forecast System (IFS) of the European Center for Medium-range Weather Forecasts (ECMWF) in order to represent consistent MJO air-sea interactions. Woolnough et al. (2007) showed that ocean/atmosphere coupled predictions of the $\mathrm{MJO}$ were superior to predictions produced by persisting the inital SST conditions. Using the same coupled model, Vitart et al. (2007) showed that the MJO predictability is further increased when improving the parameterization of the atmospheric component, especially in terms of convection. These studies concluded that the simulation of the MJO needs an accurate representation of air-sea interactions through a good representation of the intraseasonal variability and of the diurnal cycle of SST.

Several studies have shown that the use of SST products with accurate intraseasonal variability in atmosphere-only numerical models already improved the simulation of the MJO in terms variability, intensity and propagation. Reichler and Roads (2005) forced the National Centers for Environmental Prediction (NCEP) atmospheric model with weekly observed SST and reported an improvement of the MJO simulation compared to a model forced by a SST climatology. Kim et al. (2008) forced the Seoul National University atmospheric GCM with observed SST at monthly, weekly, and daily temporal resolutions. They showed that high temporal SST variability improved the simulation of the atmospheric intraseasonal variability, the propagation of the MJO and increased the MJO forecast skill. Kim et al. (2010) also showed that the phase relationship between SST and MJO convection, even at daily temporal resolution, became distorted rapidly as the forecast lead time increased. The same phase relationship was maintained when using a coupled model, suggesting that coupling is needed to extend MJO predictability.

In recent years the increasing number of satellite instruments has enhanced the developement of SST analysis products, such as those from the Group for HighResolution Sea Surface Temperature (GHRSST, see Donlon et al., 2007; http://www.ghrsst-pp.org/). Among the GHRSST products, the recent $1 / 4^{\circ}$ daily OSTIA (Operational Sea Surface Temperature and Sea-Ice Analysis) SST reanalysis (Roberts-Jones et al., 2012) spans the period January 1985-December 2007. This product uses both satellite retrievals from the Advanced Very High Resolution Radiometer (AVHRR) and the Along Track Scanning Radiometer (ATSR) and in-situ data. The $1 / 4^{\circ}$ daily AVHRR-only reanalysis (Reynolds et al., 2007) also provides a consitent SST dataset from September 1981 onwards. Such long-term SST reanalyses can be used in hindcasts of atmospheric patterns such as the MJO in oder to assess the performance of an atmospheric model. Their potential impact on the quality of the hindcasts has first to be assessed. As a comparison, the ECMWF hindcasts and the ERA interim reanalysis (Dee et al., 2011) use SST from different sources according to the considered period: the $1 \times 1^{\circ}$ weekly NCEP 2 D-VAR reanalysis from January 1981 to June 2001 (Reynolds et al., 2002), the $1 \times 1^{\circ}$ weekly NCEP OIv2 SST reanalysis from July 2001 to December 2001 (Reynolds et al., 2002), the daily $1 / 2^{\circ}$ Real Time Global (RTG) SST analysis from January 2002 to January 2009 (Gemmill et al., 2007) and the $1 / 20^{\circ}$ daily OSTIA from February 2009 onwards (Donlon et al., 2011). Before 1981 and the satellite era, the ECMWF reanalyses used the Hadley Centre Sea Ice and Sea Surface Temperature dataset (HADISST1) consisting of monthly SST and Sea Ice fields produced by the UK Met Office (Rayner et al., 2003).

This work is an attempt to assess the performance of the ECMWF IFS in hindcasting winter MJO events when forced by different SST products at different temporal resolutions starting from the same ERA interim inital conditions. The winter 1992/1993 MJO is used as benchmark case at ECMWF, as in Woolnough et al. (2007) and Vitart et al. (2007). As a reference, the IFS is forced with the observed SST used to produce ERA interim. Then the MJO forecast skill of the IFS is estimated when forced with the daily OSTIA and AVHRR-only SST reanalyses. The impact of the temporal resolution (daily, weekly, monthly) of the respective SST products is assessed by applying temporal running means to the SST fields. Then, the impact of changing the SST forcing fields from the reference (ERA interim SST) to the OSTIA and AVHRR-only reanalyses is investigated through the MJO forecast skill, the propagation of the MJO convection, the phase relationship between SST and the MJO convection, and the comparison with coupled MJO hindcasts.

In the following, Sect. 2 will describe the SST products. Section 3 will focus on the MJO experiments and their skill scores. Section 4 will investigate the phase relationship between SST and the MJO convection in the forced and coupled experiments. Section 5 will discuss the results and draw the conclusions of this study. 


\section{SST products}

\subsection{Description}

For the 1992-1993 time period, ERA interim SST fields (referred to as ERAi SST) come from the NCEP 2D-VAR SST, originally a weekly $1^{\circ} \times 1^{\circ}$ analysis (Reynolds et al., 2002) available from 1981. This analysis combines the information from in-situ data (from ships and buoys) from the Comprehensive Ocean-Atmosphere Data Set (COADS before 1998) and the Global Telecommunication System (GTS after 1998) and from the AVHRR satellite. In-situ data provide a largescale bias correction of the satellite data. The bias correction is done using a preliminary 2D-VAR analysis of the difference between weekly satellite data and in-situ data on a $1^{\circ}$ grid (Reynolds et al., 2002). In-situ data and corrected satellite observations are then analysed using a 2D-VAR procedure. Weekly SSTs were then daily linearly interpolated for the building of ERA interim (Fiorino, 2004). Compared to the version 2 of the Optimal Interpolation procedure (OIv2, Reynolds et al., 2002), the 2D-VAR is known to have a too large correlation scale $(1650 \mathrm{~km})$ in the bias correction step and to produce somewhat smoother SST fields and smaller meridional gradients in the equatorial Pacific (Fiorino, 2004).

The daily $1 / 4^{\circ}$ AVHRR-only reanalysis (Reynolds et al., 2007) uses similar data as the 2D-VAR SST but more upto-date (ICOADS dataset and AVHRR satellite). All data are used for a given day and the SST are analysed using the OIv2 procedure. OIv2 includes a temporal smoothing within the 3-day assimilation window where the middle day (the day of the analysis) is weigthed higher than the other two days. The error correlation scales range from 50 to $200 \mathrm{~km}$ according to the geographical region. The diurnal cycle of SST is ignored in the analysis. However, as the OI analysis is a daily average SST that is bias adjusted using a spatially smoothed 7-day insitu SST average, the impact of the dirunal cycle is reduced.

The daily $1 / 4^{\circ}$ OSTIA reanalysis (Roberts-Jones et al., 2012) combines the information from the ICOADS in-situ dataset, the Ocean Sea Ice Satellite Application Facility (OSI SAF) sea ice concentration data, the AVHRR satellite and the ATSR instruments. The SST is analysed using a multiscale OI-type scheme in a $72 \mathrm{~h}$ window centred on 12:00 UTC on the analysis day (see Roberts-Jones et al., 2012, for more details). Higher weight is given to observations closest to the analysis day. Two error correlation scales -10 and $100 \mathrm{~km}$ - are used, depending on the region and the input data. The OSTIA product provides an estimate of the foundation SST as defined by the GHRSST, i.e. a SST free of diurnal warming.

\subsection{General comparison}

The main differences between OSTIA/AVHRR and ERAi SST come from their repective mean state and the additional variability associated to their daily temporal resolu- tion. On average over the winter 1992-1993, the OSTIA SST are overall colder than ERAi SST by $0.18^{\circ} \mathrm{C}$ in the Tropics. Apart from some warmer patches, OSTIA SST are particularly colder (sometimes by more than $0.4^{\circ} \mathrm{C}$ ) in the western part of the Maritime Continent, in the Pacific cold tongue and in the Tropical Atlantic (Fig. 1a). AVHRR SST are also overall colder than ERAi SST in the Tropics, particularly in the western Indian Ocean (from 0.2 to $0.8^{\circ} \mathrm{C}$ colder) over the Maritime Continent and in the western Pacific (Fig. 1b). The intraseasonal variability of each SST product is estimated as the standard deviation of SST anomalies with respect to the 1985-2006 climate over the winter 1992-1993. OSTIA and AVHRR daily products show much more intraseasonal variability than the ERAi SST (only daily interpolated from a weekly product) all over the Tropical area (Fig. 2). These two products, for example, capture the small scale variability around the Pacific cold tongue probably associated with Tropical instability waves. The AVHRR reanalysis shows slightly more variability than OSTIA in the eastern Indian Ocean, the tropical Pacific and Atlantic Oceans, and slightly less in the western and southern Indian Ocean (Fig. 2a, b).

At the TAO station $2^{\circ} \mathrm{S}-156^{\circ} \mathrm{E}$, the OSTIA and AVHRR products seem overall closer to in-situ observations than ERAi SST over the winter 1992-1993 (Fig. 3). As expected, OSTIA and AVHRR SST show more variance than ERAi SST $(0.16$ and 0.17 versus 0.9$)$, which matches the TAO observations (variance of 0.17). Among the three SST products, OSTIA shows the best correlation with the observations (0.9). AVHRR and ERAI have similar correlations (0.75). The relatively low correlation of AVHRR SST is due to large variability signals characterized by extrema of SST that are not found in the other products. These extrema also lead to a relatively high root mean square error $(0.32$ versus 0.21 for OSTIA and 0.27 for ERAi). These time series show that the atmosphere of the MJO hindcasts will see quite different boundary conditions according to the chosen forcing set.

In the context of the MJO hindcasts, the SST fields from AVHRR-only and OSTIA reanalyses are interpolated on the spectral grid of the atmospheric model $T_{L} 159(1.125 \times 1.125$ at the Equator) with an inverse-distance-weighted interpolation scheme using the information of the 8 closest grid points. The interpolation smoothes the spatial variability of the AVHRR and OSTIA fields, but the resulting SST are never as smooth as ERAi SST.

\section{MJO experiments}

\subsection{Experiment settings}

The experimental settings of the MJO hindcasts are similar to the ones described in Woolnough et al. (2007) and Vitart et al. (2007). Briefly, each experiment consists of a series of 32-day forecasts using a five-member ensemble initialized at 00:00 UTC each day from 15 December 1992 

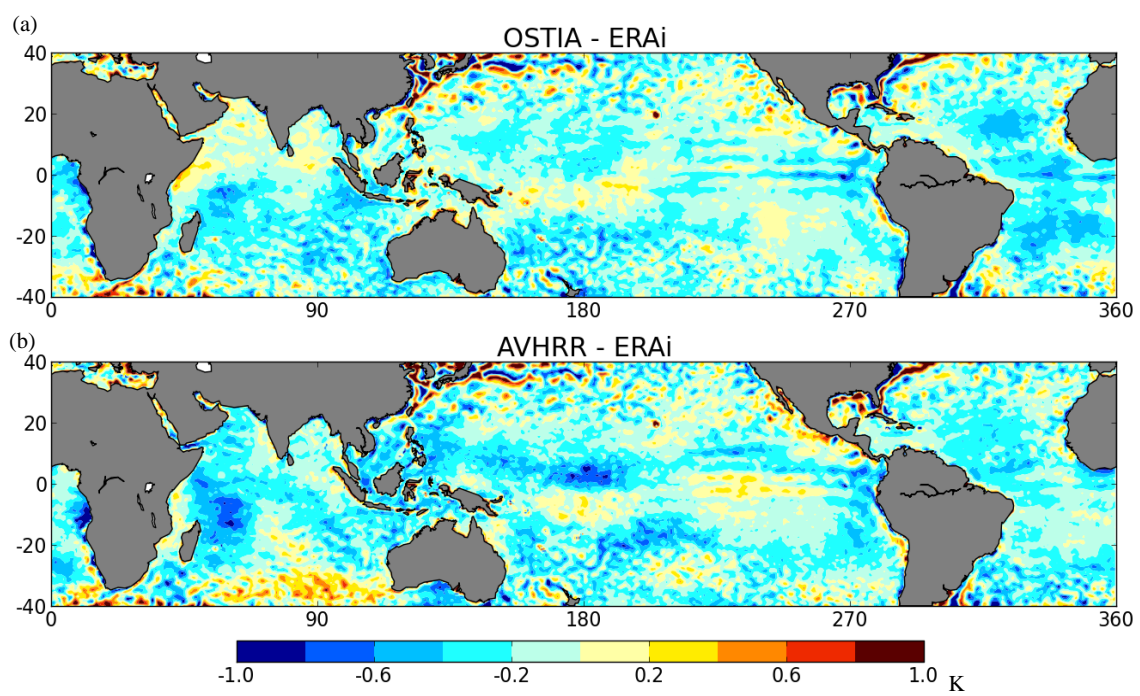

Fig. 1. (a) Difference between OSTIA and ERAi SST (in K) averaged over the winter (December to March) 1992-1993 in the Tropics. (b) Same as (a) for AVHRR SST.

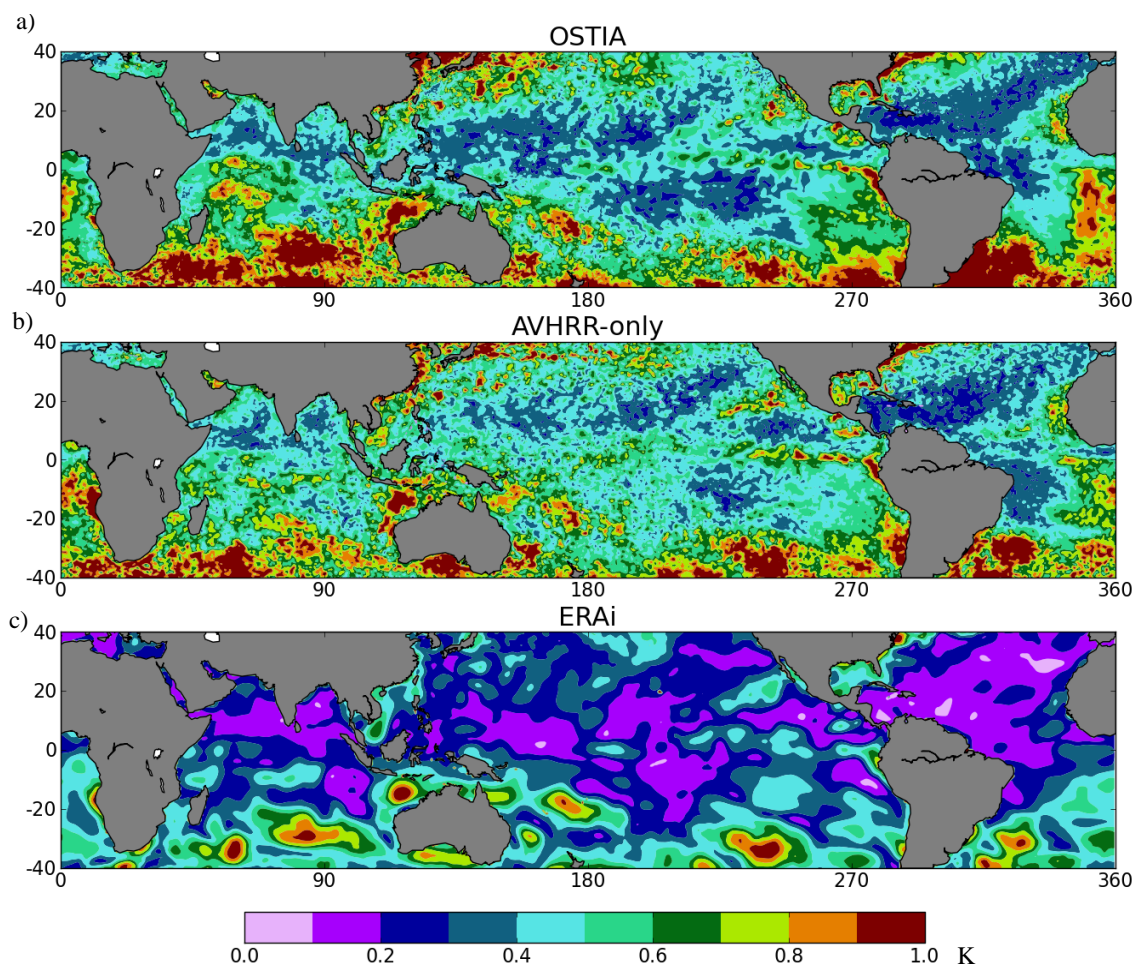

Fig. 2. (a) Standard deviation (in K) of OSTIA SST anomalies over the winter (December to March) 1992-1993 in the Tropics. (b) and (c) Same as (a) for AVHRR SST and ERAi SST, respectively. Anomalies are estimated with respect to the 1985-2006 climate.

to 31 January 1993. The 32-day forecasts are used operationally at ECMWF for the prediction of the MJO. Series of monthly forecasts allow to examine the evolution of the MJO for evolving initial conditions (Kim et al., 2008). Initializing the model through different phases of the MJO helps detecting the stage within the prediction period where the atmospheric model loses skill. In our experiments, the atmo- spheric component is the ECMWF IFS cycle 36R4 used in the ECMWF seasonal forecast sytem (Molteni et al., 2011). The horizontal resolution is $T_{L} 159$ with 62 vertical levels. The atmospheric initial conditions come from the ERA interim reanalysis (Dee et al., 2011). A skin layer scheme has been implemented in the IFS to simulate the diurnal 


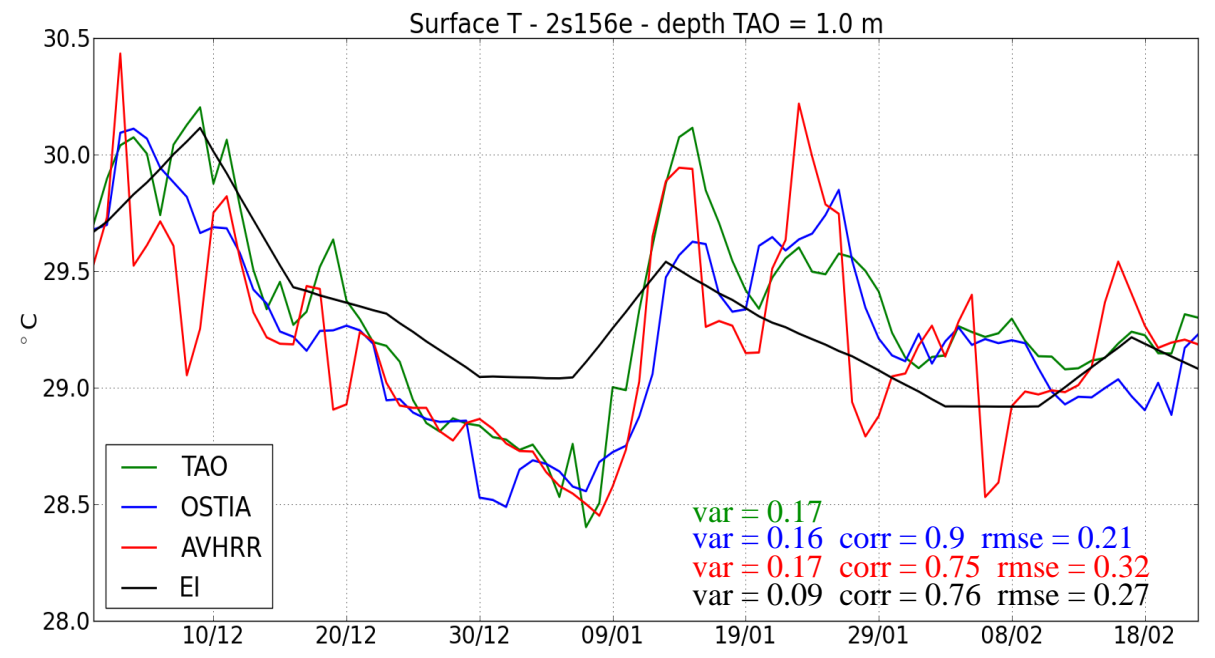

Fig. 3. In-situ SST (temperature observed at $1 \mathrm{~m}$ depth, TAO, green line), OSTIA SST (OSTIA, blue line), AVHRR SST (AVHRR, red line) ERAi SST (EI, black line) at the TAO station $2^{\circ} \mathrm{S}-156^{\circ} \mathrm{E}$ from December 1992 to March 1993 . SST in ${ }^{\circ} \mathrm{C}$. On the background is written the variance (var) associated to each SST product. For the OSTIA, AVHRR and ERAi SST, the correlation (corr) and the root mean square error (rmse) with respect to the TAO SST are also provided.

variations of SST (see Zeng and Beljaars, 2005, and Takaya et al., 2010).

For comparative purposes, a coupled ocean-atmosphere version of the IFS is also used in Sect. 4.3. The atmospheric component is the same as in atmosphere-only mode. The oceanic component is the NEMO (Nucleus for European Modelling of the Ocean, Madec, 2008) ocean GCM (OGCM) version 3.0 with 42 vertical levels, a resolution in the extratropics of about $1^{\circ}$ and a higher meridional resolution in the equatorial region (about $0.3^{\circ}$ ). The coupling frequency is $3 \mathrm{~h}$. This coupled model is used in the ECMWF seasonal forecast system and more details are given in Molteni et al. (2011).

In the main part of the study, three sets of MJO experiments (see Table 1) are conducted in atmosphere-only mode. First, as a reference experiment, the atmosphere is forced by ERAi SST that are daily interpolated from a weekly reanalysis (see Sect. 2.1). An additional experiment uses ERAi SST at a monthly resolution. The second set of experiments uses the OSTIA SST reanalysis at daily, weekly and monthly resolutions. To assess the impact of the difference of mean state between OSTIA and ERAi, an additional experiment is run where the mean state of OSTIA SST is corrected in each forecast by removing the averaged difference between OSTIA SST and ERAi SST over the forecast length. The third set of experiments uses the AVHRR-only SST reanalysis at daily, weekly and monthly resolutions. As for the OSTIA product, the experiment with correction of the mean state with respect to ERAi SST is also run. The transition from daily to weekly and from daily to monthly resolution is performed by applying a running mean on the original SST fields centred on the day of the corresponding forecast lead time.
Table 1. Experiments performed with the ECMWF model in atmosphere-only mode and their respective SST forcing for the MJO case of the winter 1992-1993.

\begin{tabular}{cccc}
\hline & ERAi SST & OSTIA SST & AVHRR SST \\
\hline 1 & original ERAi & original OSTIA & original AVHRR \\
2 & & weekly OSTIA & weekly AVHRR \\
3 & monthly ERAi & monthly OSTIA & monthly AVHRR \\
4 & & Corr. mean state & Corr. mean state \\
\hline
\end{tabular}

\subsection{Diagnostic procedure}

The skill of prediction of the MJO is evaluated according to the method described in Wheeler and Hendon (2004). This method considers that the intraseasonal variability of the MJO can be captured by a combined Empirical Orthogonal Function (EOF) analysis of the anomalies (with respect to the 1991-2003 climate) of the zonal wind at 200-hPa and 850-hPa and of the Outgoing Longwave Radiation (OLR) averaged between $10^{\circ} \mathrm{S}$ and $10^{\circ} \mathrm{N}$. The zonal winds at $200 \mathrm{hPa}$ and $850 \mathrm{hPa}$ capture the convergence and divergence features associated with the MJO convective and suppressed phases. Being influenced by the cloud cover, OLR anomalies are a proxy the presence or absence of the convective centre of the MJO. Wheeler and Hendon (2004) showed that the variance of the principal components (PC) of the leading pair of EOFs is concentrated at intraseasonal periods (30-80 days), while the other EOFs do not contain much intraseasonal signal. Most of the MJO variability is thus described by the two first EOFs. The projection on these two EOFs acts as an effective filter for the intraseasonal frequencies of the MJO (Wheeler and Hendon, 2004). 

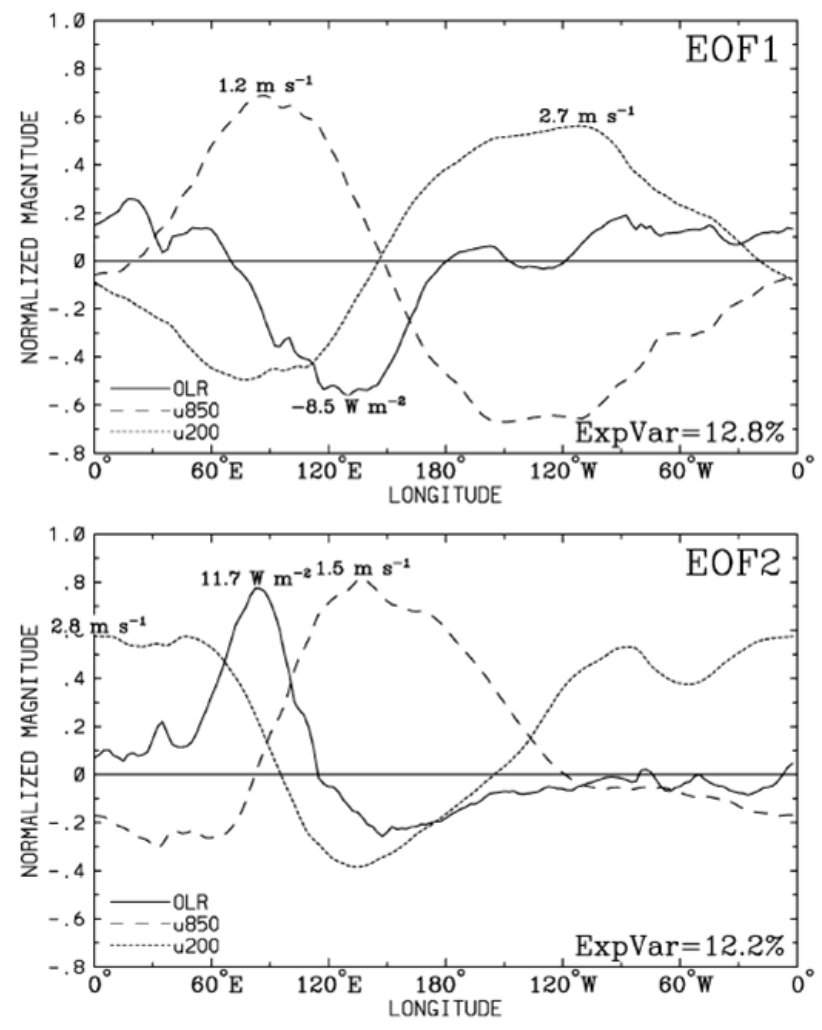

Fig. 4. Figure 1 from Wheeler and Hendon (2004). Spatial structures of EOFs 1 and 2 of the combined analysis of anomalies of OLR, and of zonal wind $(u)$ at 850 , and $200 \mathrm{hPa}$. The variance explained by the respective EOFs is $12.8 \%$ and $12.2 \%$.

EOF1 and EOF2 can describe the eastward propagation of the large-scale, vertically oriented circulation cells of the MJO and all the active and suppressed MJO phases (Fig. 4). OLR minima reflect the position of the convective centre of the MJO. They are associated with succesive negative and positive anomalies of $850 \mathrm{hPa}$ zonal winds and positive and negative anomalies of $200 \mathrm{hPa}$ winds, indicating a convergence at the surface and a divergence in the upper troposhere, respectively (Fig. 4). OLR extrema and wind convergence/divergence are almost in phase over the Maritime Continent on EOF1 and the Indian Ocean on EOF2. The phase relationship between zonal winds convergence/divergence and OLR is less clear over the Pacific and the Western Hemisphere. According to the sign of the associated PC, the convective centre on EOF1 is located over the Maritime Continent $(\mathrm{PC} 1>0)$ or over the Western Hemisphere and Africa $(\mathrm{PC} 1<0)$. On EOF2, the convection is over the Pacific Ocean $(\mathrm{PC} 2>0)$ or over the Indian Ocean $(\mathrm{PC} 2<0)$.

The recommended score of the MJO forecast relies on the correlation of the monthly ensemble-mean forecasts with the two first PCs of the combined EOFs estimated from the ERA interim atmospheric reanalysis. Dee et al. (2011) showed ERA interim produced a better MJO signal and better ini- tial conditions for MJO forecasts than the previous ECMWF reanalyses. Section 4.1 also shows that the OLR from ERA interim is very close to the satellite observations on intraseasonal time scales. The method for computing the MJO scores of this study is detailed in Vitart et al. (2007). According to Woolnough et al. (2007), two MJO events occur between mid-December 1992 and February 1993. The 47 starting dates of the experiments include all the phases of these MJO events as identified by the combined EOF analysis. Plus, each forecast captures each phase of the MJO at least once.

\subsection{Scores}

The impact of the temporal resolution of the SST forcing on the forecast skill is first addressed by comparing the MJO hindcasts performed with daily, weekly and monthly SST fields from the OSTIA and AVHRR-only reanalyses. Concerning the OSTIA product, the correlations of the ensemblemean forecast with the two principal components of the combined EOF are similar for the three temporal resolutions until day 6 of the forecast (Fig. 5a). The daily and weekly experiments show similar scores on PC1 and 2. The skill is higher than 0.8 up to days 17 and 19 on PC1 and 2, and remains significant (correlations higher than 0.6) until days 22 and 23, respectively. With respect to higher resolution experiments, the monthly experiment shows a loss of skill of at least 2 days from day 10 throughout the forecast lead time on PC1. On PC2, the monthly experiment maintains a good skill until day 13 that rapidly decays to ultimately show a loss of 6 days of significant skill.

The monthly experiment using the AVHRR product shows very similar skill as its OSTIA equivalent but the gap between the monthly and weekly/daily resolutions is reduced with a loss of signifiant skill of 1 to 2 days on PC1 and 2 to 3 days on PC2. As for OSTIA, the daily and weekly experiments show similar scores (Fig. 5b). The scores of the weekly experiment looks a bit better than the daily one, especially on PC1 with a gain of significant skill of 1 day at day 22 . On PC2, both daily and weekly experiments show significant skill until day 20. Differences between weekly and daily experiments nevertheless remain within the forecast spread.

At full temporal resolution, the scores of the OSTIA product are better than for AVHRR, especially on PC2 where the OSTIA experiment shows a gain of skill of 3 days (Fig. 5c). But the MJO scores obtained when using these two SST products remain lower than when using ERAi SST. Both OSTIA and AVHRR experiments show a loss of significant skill of 2 days on PC1, and much more on PC2 where the predictability when using ERAi SST stays high throughout the forecast with correlations higher than 0.7. When ERAi SST have a monthly resolution, the MJO scores are also degraded and similar as when using monthly OSTIA and AVHRR SST.

Another interesting point is that weekly and daily OSTIA/AVHRR-forced experiments produce similar scores, showing that the additional variability associated to the daily 
a)

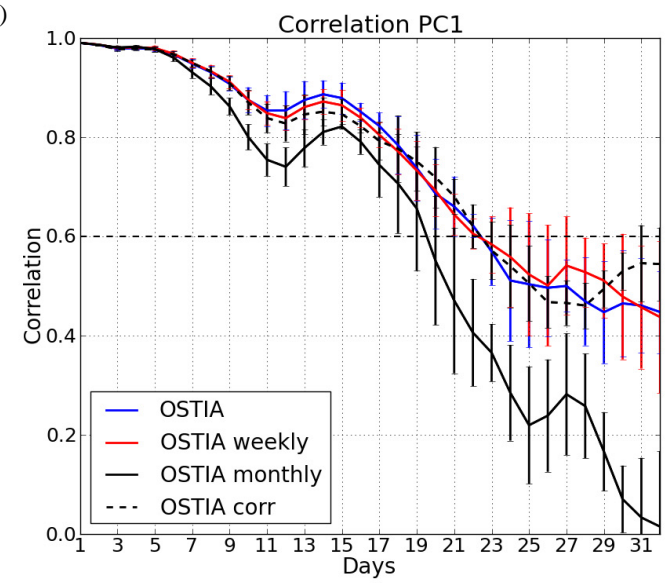

b)

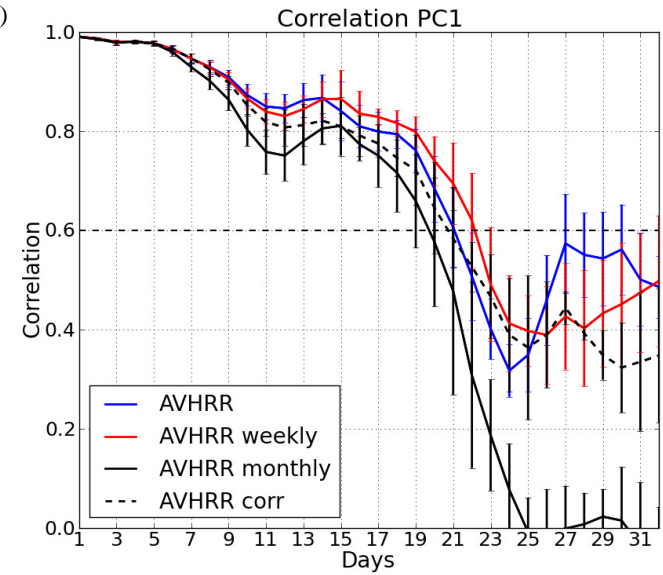

c)

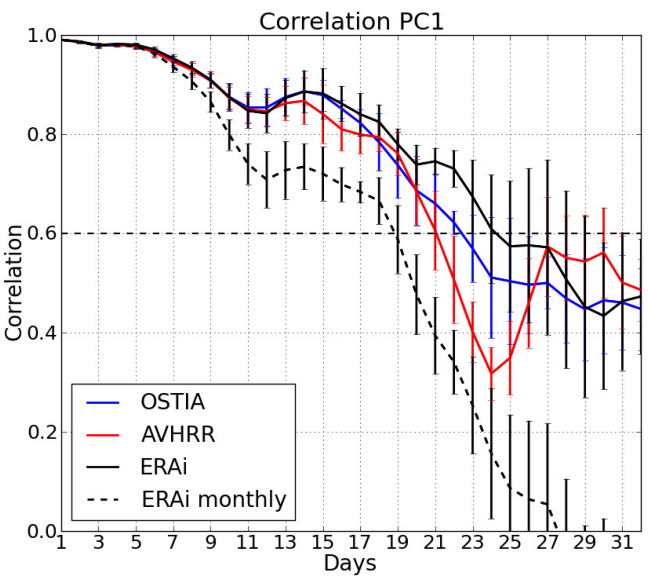

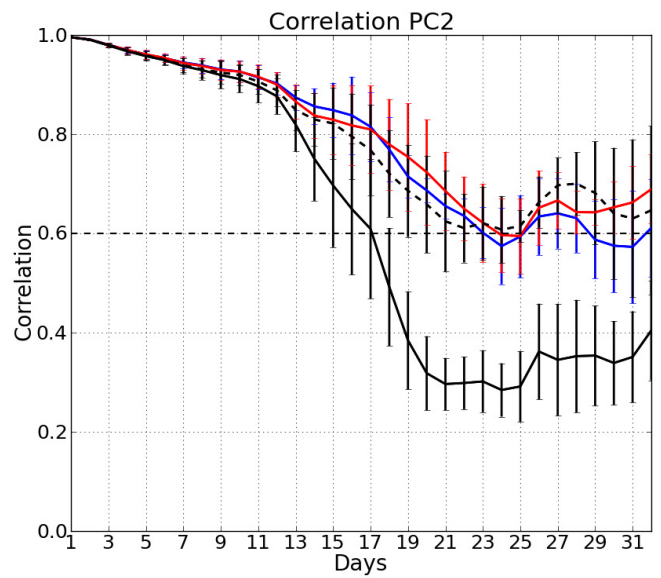
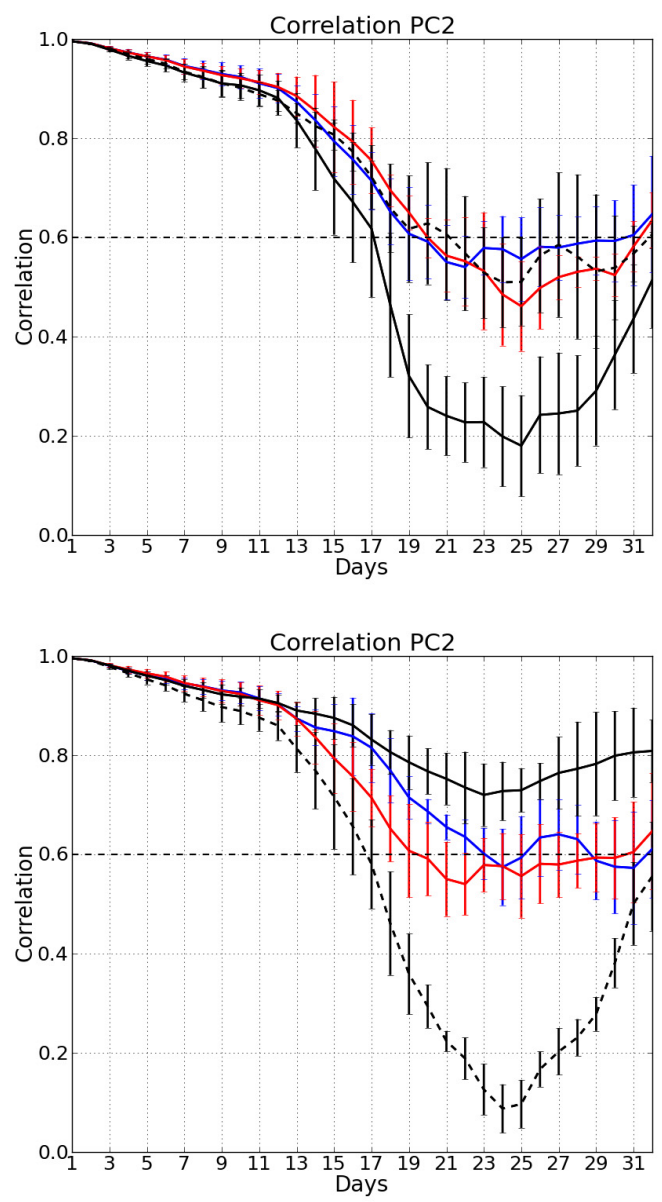

Fig. 5. Correlation of the PC1 (left) and PC2 (right) from the reanalysis with the ensemble mean forecast time series, based on 47 start dates (15 December 1992 to 31 January 1993), for the atmosphere-only experiments performed with the ECMWF forecast system at the $T_{L} 159$ resolution. (a) Forcing by OSTIA SST at original (daily) temporal resolution (black line), weekly (blue line) and monthly (red line) temporal resolutions. The black dashed line is the forcing, where OSTIA SST mean state is corrected with respect to ERAi SST. (b) Same as (a) for AVHRR SST. (c) Forcing by original OSTIA (blue line) and AVHRR (red lines) products and by ERAi SST at their original (weekly) and monthly resolutions (solid and dashed black lines, respectively). The signifcance level (correlation of 0.6) is highlighted by a horizontal black dashed line. Error bars stand for the ensemble spread. 

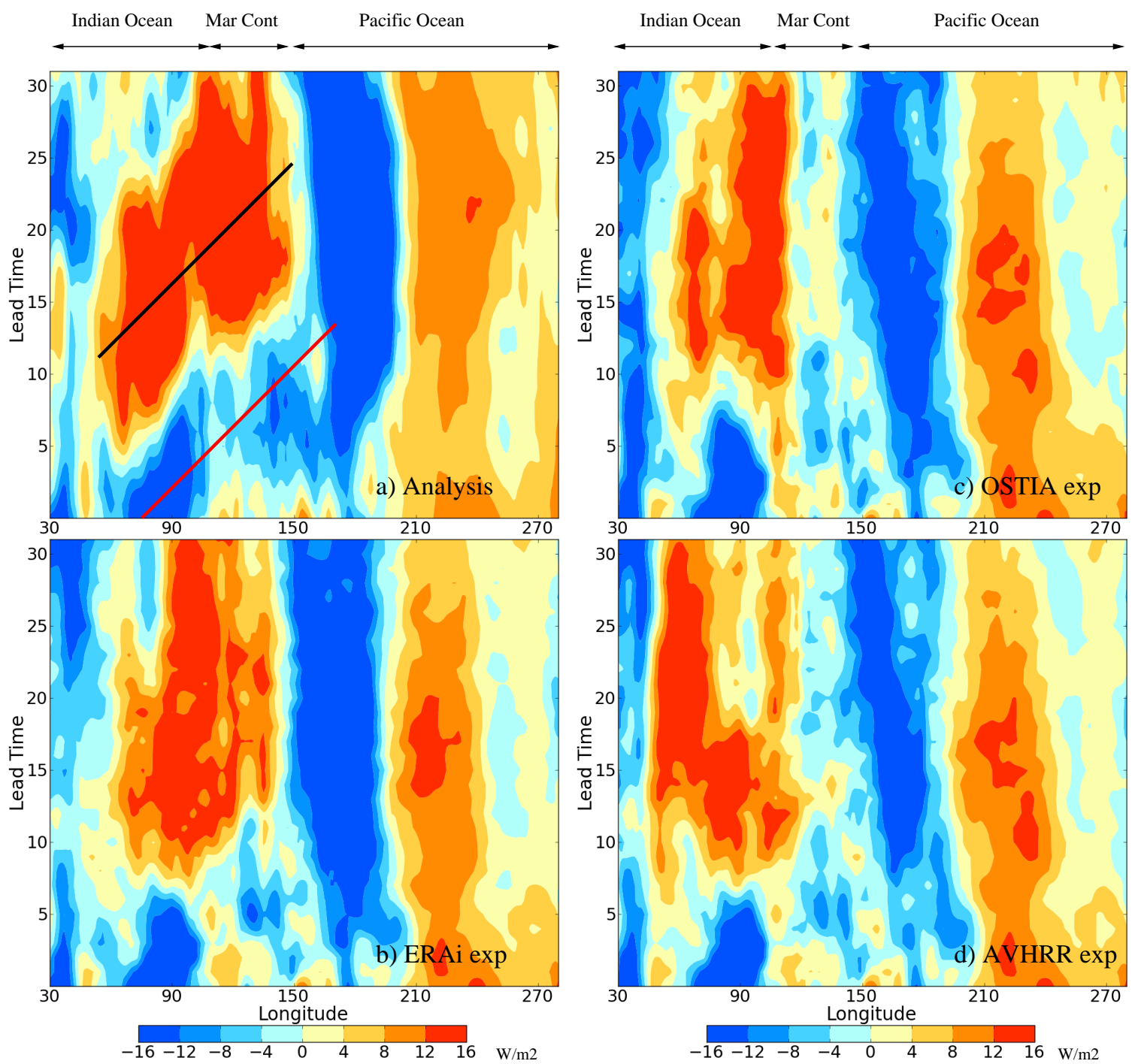

Fig. 6. Longitudinal hovmoller diagrams of the ensemble-mean OLR anomalies (in $\mathrm{W} \mathrm{m}^{-2}$ ) averaged between $10^{\circ} \mathrm{S}$ and $10^{\circ} \mathrm{N}$ for starting dates when the convective centre of the MJO is over the Indian Ocean. Negative anomalies indicate active convection, while positive anomalies indicate suppressed convection. (a) ERA interim reanalysis, (b) ERAi experiment, (c) OSTIA experiment, (d) AVHRR experiment. The red and black lines indicate the propagation of the active and suppressed phases of the MJO, respectively.

frequency of the OSTIA and AVHRR-only reanalyses is not the reason why forcing the atmosphere with these two products does not provide as good results as when using ERAi SST that are derived from weekly fields (Fig. 5a, b). Similarly, there is no improvement of the MJO scores when correcting the mean state of the OSTIA and AVHRR-only products with respect to ERAi SST in the MJO hindcasts. The differences in MJO skills with respect to the ERAi experiment are thus not directly linked to the mean state and time frequency of the two GHRSST products. Although these two aspects are likely to be important for the MJO prediction, in our experiments their repsective impact may be masked by other deficiencies.

\subsection{MJO signal}

To visualise how the experiments forced by the three SST products differ, the propagation of the MJO signal in the forecasts is tracked in longitudinal hovmoller diagrams of ensemble-mean OLR anomalies averaged between $10^{\circ} \mathrm{S}$ and $10^{\circ} \mathrm{N}$. In Fig. 6, the forecasts and their equivalents in the ERA interim reanalysis are averaged for starting dates when the convective centre of the MJO is over the Indian Ocean. In the reanalysis (Fig. 6a), the MJO convective centre (negative OLR anomalies) propagates from the Indian to the central Pacific Ocean and is followed by a phase of suppressed convection (positive OLR anomalies) a few days later. The ERAi experiment simulates correctly this propagation but the MJO 


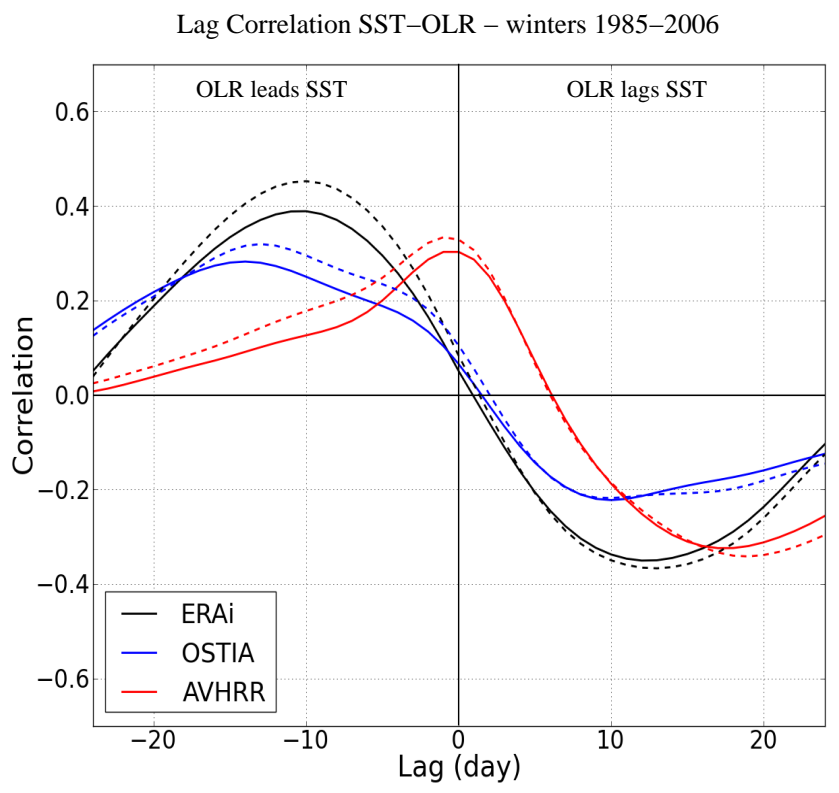

Fig. 7. Lag correlation coefficient between OLR and SST anomalies over the region $5^{\circ} \mathrm{S}-5^{\circ} \mathrm{N}, 60^{\circ}-95^{\circ} \mathrm{E}$ over the winters (DecemberFebruary) 1985-2006 using SST fields from ERA interim (ERAi, black lines), OSTIA (blue lines) and AVHRR (red lines) and OLR fields from either ERA interim (solid lines) or NOAA satellites (dashes lines). The lags are in days. OLR leads SST for negative lags and OLR lags SST for positive lags.

active and suppressed phases are much weaker than in the reanalysis (Fig. 6b). The weakening is particularly marked when the convection reaches the Maritime Continent that is know as a barrier for the MJO simulation (Inness et al., 2003). In the OSTIA experiment (Fig. 6c), the MJO convective signal is even weaker over the Maritime Continent and its eastern propagation is hardly visible. There is no visible propagation of the suppressed phase that is stuck over the Maritime Continent. In the AVHRR experiment (Fig. 6d), the propagation of the convective phase of the MJO is slightly more pronounced but a signal of suppressed convection remains over the Indian Ocean throughout the rest of the forecast without any sign of the following convective signal that appears in the ERA interim reanalysis.

\section{Phase relationship between SST forcing and MJO convection}

The only difference between the experiments is the SST fields that the atmospheric model receives as lower boundary conditions. Kim et al. (2008) and Kim et al. (2010) showed that, in the observations, the suppressed MJO convection leads enhanced SST and that active MJO convection follows enhanced SST after several days. They also show that, in MJO hindcasts, according to the SST that the atmosphere sees, this relationship becomes more or less distorted with increased lead time, leading to the degradation of the hindcasts over the winters 1998-2004. One can thus expect to see the differences in the scores of the MJO experiments described in Sect. 3.3 being reflected by obvious differences in the corresponding SST-convection phase relationship.

\subsection{Phase relationship between SST and OLR: reanaly- sis and observations}

The SST-convection phase relationship is estimated in the Indian Ocean over the winters (December-February) 19852006 chosen as the common winter period for ERAi, OSTIA and AVHRR SST products. The observed OLR (indicative of the convection) comes from the National Oceanic and Atmospheric Administration (NOAA) daily interpolated OLR (see Liebmann and Smith, 1996). The NOAA interpolated OLR is produced from the NOAA satellite retrievals on a $2.5^{\circ} \times 2.5^{\circ}$ grid and is available from 1979 onwards. The phase relationship between SST and convection is produced from filtered SST and OLR anomalies with respect to their respective 1985-2006 mean averaged in the Indian Ocean box $5^{\circ} \mathrm{S}-5^{\circ} \mathrm{N}, 60^{\circ}-95^{\circ}$ E. Following the method of Kim et al. (2008), for each date, the interannual variability of SST and OLR is removed by substracting their respective 32-day mean (the 32 days following the considered date). The intraseasonal variability is then extracted from SST and OLR by applying a 5-day running mean. When using ERAi SST and NOAA OLR, the lag-correlation between SST and OLR shows a near-quadrature phase relationship. The quadrature is defined by a 0 correlation at lag 0 and correlations (either positive or negative) peaking at lags corresponding to a quarter of the period of the considered signal. In Fig. 7, positive OLR anomalies (suppressed convection) lead enhanced SST, and negative OLR (enhanced convection) lag enhanced SST after several days. The correlations peak at lag -10 days $(0.45)$ and +12 days $(-0.38)$. The phase relationship in ERA interim is similar in shape but with slightly smaller amplitudes: 0.39 and -0.37 . When using OSTIA SST with either NOAA or ERA interim OLR, the phase relationship still has a near-quadrature shape but the correlation peaks are shifted by almost 3 days toward the negative lags. The amplitude of the relationship is also weaker than in ERA interim, with correlation peaking around 0.27 and -0.21 . The OSTIA reanalysis thus provides a relatively weak relationship between SST and the observed MJO convection. When using AVHRR SST, the phase relationship is not quadratic anymore. The maximum correlation (0.3) coincides with the 0 lag and the minimum correlation $(-0.33)$ only happens at lag +17 days. The AVHRR-only reanalysis is thus off the expected phase relationship between ocean and MJO convection in the Indian Ocean. 
Lag correlation SST-OLR - winters 1985-2006
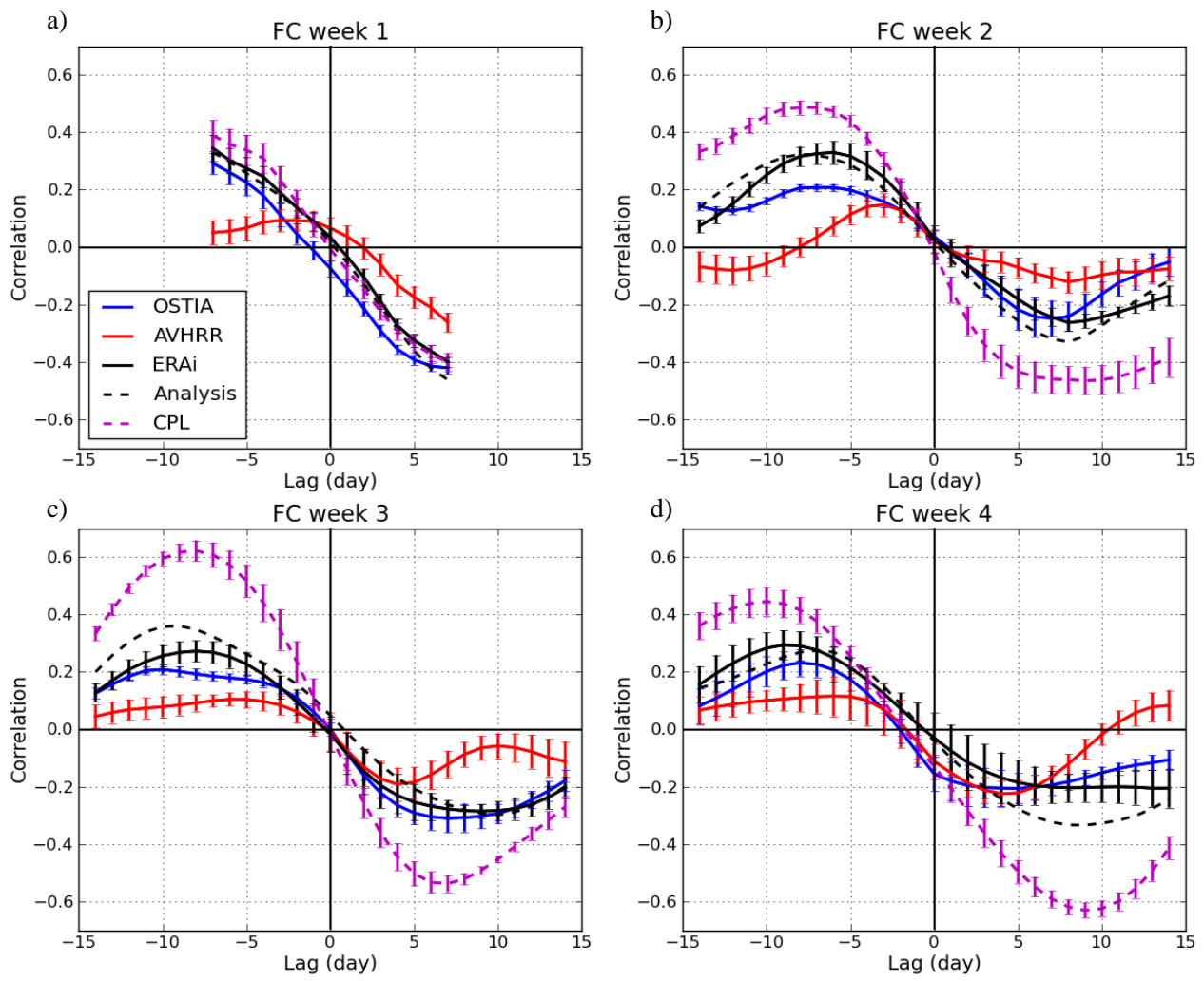

Fig. 8. Lag correlation coefficient between OLR and SST anomalies over the region $5^{\circ} \mathrm{S}-5^{\circ} \mathrm{N}, 60^{\circ}-95^{\circ} \mathrm{E}$ averaged according to the forecast week of the experiments conducted over 22 winters (1985-2006). OSTIA, AVHRR and ERAi experiments are the blue, red and solid black lines, respectively. Their equivalent in the ERA interim reanalysis is the black dashed line. For comparative purposes, the coupled experiment is plotted in dashed purple. (a) Week 1, (b) 2, (c) 3 and (d) 4. Error bars stand for the ensemble spread.

Table 2. Experiments performed with the ECMWF model for the MJO the winters 1985-2006.

\begin{tabular}{cc}
\hline & Description \\
\hline ERAi & forced by original ERAi SST \\
OSTIA & forced by original OSTIA SST \\
AVHRR & forced by original AVHRR SST \\
CPL & coupled to the NEMO OGCM \\
\hline
\end{tabular}

\subsection{Phase relationship between SST and OLR: forced experiments}

To investigate the relationship between SST and convection as simulated in the MJO hindcasts, additional experiments (Table 2) are conducted over the winters 1985-2006. These experiments include 5 32-day forecasts per winter, every 15 days from 1 December to 1 February. The configuration of the atmospheric model is the same as for previous experiments (see Sect. 2.1). The atmosphere is forced by the OSTIA and AVHRR-only reanalyses and by the ERAi SST. As mentioned in the Introduction, over 1985-2006, ERAi SST are produced from the $1 \times 1^{\circ}$ weekly NCEP $2 \mathrm{D}$-VAR reanalysis from January 1981 to June 2001 , the $1 \times 1^{\circ}$ weekly NCEP OIv2 SST reanalysis from July 2001 to December 2001 and the daily $1 / 2^{\circ}$ RTG SST analysis from January 2002.

These 22-winter experiments provide enough data to investigate the phase relationship between the SST forcing and the simulated OLR according to the forecast lead time. This relationship is estimated in a similar way as in Sect. 4.1. The interannual variability in each 32-day forecast is removed by substracting its 32-day mean. The intraseasonal variability is then extracted by applying a 5-day running mean in each forecast segment. The days prior to the 32-day forecast are padded by data from the ERA interim reanalysis before the 5-day running mean is applied. The evolution of the phase relationship between SST and OLR in the Indian Ocean $\left(5^{\circ} \mathrm{S}-5^{\circ} \mathrm{N}, 60^{\circ}-95^{\circ} \mathrm{E}\right)$ according to the lead time in the three forced experiments is compared to its equivalent in the ERA interim reanalysis. As seen in Sect. 4.1 (Fig. 7), the reanalysis shows a near-quadrature phase relationship (Fig. 8). Correlations peak around 7-10 days according to the considered forecast week. Forcing with either OSTIA SST or ERAi SST produces similar phase relationships that 

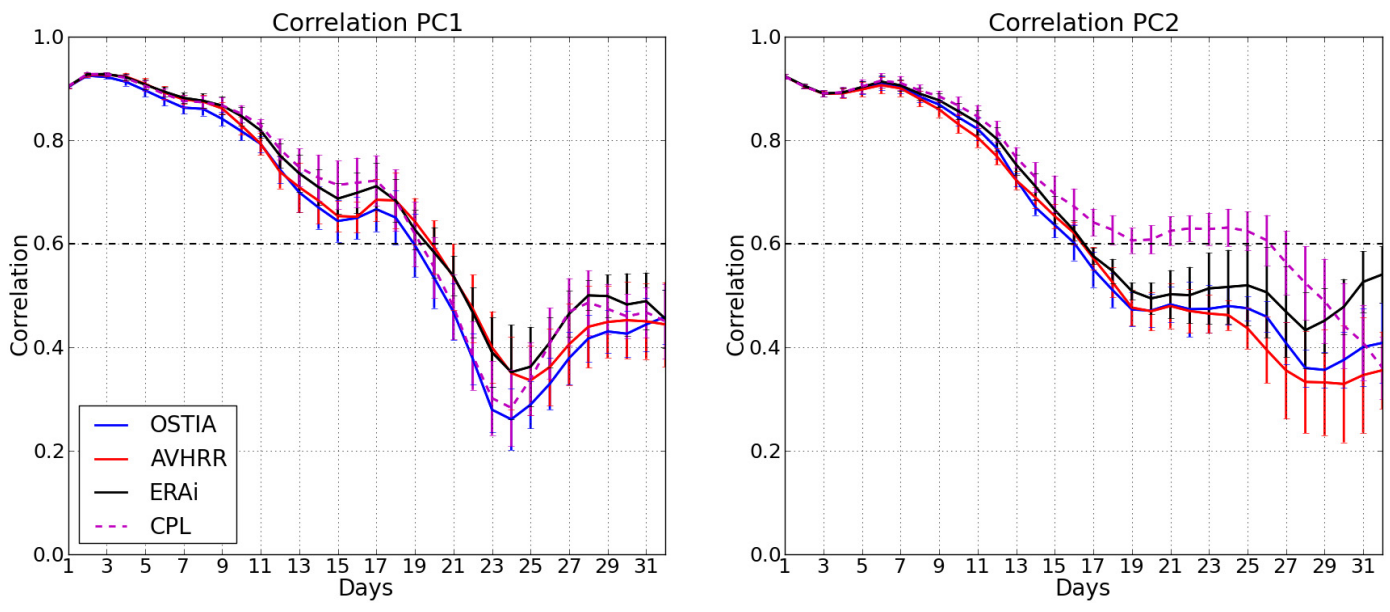

Fig. 9. Same as Fig. 5 for the experiments conducted over 22 winters from 1985 to 2006: OSTIA, AVHRR and ERAi experiments are the blue, red and black lines, respectively. For comparative purposes, the coupled experiment is plotted in dashed purple.

are, though sometimes weakened, overall close to the reanalysis until week 3 of the forecast. The forecast forced by OSTIA is nevertheless slightly shifted toward negative lags in week 1 of the forecast. The phase relationship is recovered in weeks 2 and 3 but with lower correlations than in the ERAi experiment when the lag is negative in weeks 2 and 3. The OSTIA experiment loses the quadrature phase relationship in week 4 of the forecast, while the ERAi experiment keeps some consistency with the reanalysis. When forcing with AVHRR SST, there is no quadrature phase relationship between SST and convection in week 1. The shape of the phase relationship is more consitent with the observed one (Fig. 7). In weeks 2 and 3, the quadrature shape is recovered but the correlations are very weak and the timings do not match the reanalysis. In week 4 , as in the OSTIA experiment, the quadrature is lost again.

\subsection{Phase relationship between SST and OLR: compar- ison with coupled MJO hindcasts}

For comparative purposes, the same MJO hindcasts as in Sect. 4.2 are conducted in coupled mode. The coupled experiment provides an intense quadrature phase relationship between SST and convection from week 1 up to week 3 of the hindcasts before losing it in week 4 (Fig. 8). Though more intense, this relationship is consistent with the reanalysis, the satellite observations and the hindcasts forced by ERAi SST (Figs. 7 and 8). The experiments using either OSTIA or AVHRR SST both show a lack of quadrature relationship with the MJO convection in week 1. By week 2, however, SST and convection have become in near-quadrature again. In coupled mode, however, there is no sign of lack of quadrature in week 1 . This suggests that the 3 -h coupling frequency allows atmosphere and ocean to rapidly put themselves in a quadrature phase relationship. The quadrature seems to be the preferential phase relationship the atmospheric model tends to have with its lower boundary in the Indian Ocean. This is probably what the atmospheric model is trying to recover when the phase relationship is perturbed by the switch of SST fields at the beginning of the hindcasts forced by OSTIA and AVHRR products. This initial perturbation is not optimal in the perspective of predicting MJO events, as the resulting degraded phase relationship between SST and convection implies less efficiency to maintain and propagate the MJO signal (Kim et al., 2008). This is reflected in the scores of the 22-winter MJO hindcasts that show lower forecast skill when using either OSTIA or AVHRR SST than when using ERAi SST (Fig. 9). The coupled experiment show a further gain of skill compared to the forced experiment in PC2 (Fig. 9), when the MJO active centre interacts more frequently with the ocean (see Sect. 3.2). The persistence of the skill in PC2 is consistent with the maintenance of a strong SST-convection phase relationship throughout the MJO hindcasts. Although the results of the coupled MJO hindcasts have to be further validated, they highlight the importance of atmosphere-ocean coupled processes in the simulation and prediction of the MJO.

\section{Discussion and conclusion}

SST analyses are an important component of numerical weather prediction systems. They are used to force atmospheric models in hindcast and reanalysis activities that are crucial for the improvement of the short- and extended-range weather forecasts. This study mainly explores the sensitivity of hindcasts of the MJO to a change of SST boundary conditions from ERAi SST to either OSTIA or AVHRR-only SST reanalyses. The sensitivity of the scores of the MJO hindcasts to the temporal resolution of the different SST products is also assessed. The study mainly focuses on the winter MJO 
of 1992-1993 used as a benchmark case for the ECMWF monthly forecasting system (Vitart et al., 2007).

Whatever the considered product, a SST with monthly temporal resolution is not optimal for hindcasting the 19921993 MJO. The resulting scores show a relative loss of at least 2 days of significant skill compared to a daily or weekly SST product (Fig. 5a, b). This is consistent with results from Kim et al. (2008) and Klingaman et al. (2008) who showed a relative loss of predictability in the Tropics when forcing the atmosphere with a monthly SST product. Daily and weekly SST products however show similar forecast skills. When switching from ERAi SST to either OSTIA or AVHRR SST, the skill of the 1992-1993 MJO hindcast is relatively degraded. Additional experiments show that the differences between these two SST products and the ERAi SST in terms of mean state and temporal variability (see Figs. 1 and 2) are not the main reasons for this degradation.

Instead, this study suggests that the relative loss of skill comes from a distortion of the phase relationship between the SST and the MJO convection when switching from ERAi SST to either OSTIA or AVHRR SST. Computing this phase relationship from ERAi SST and observed OLR provides the quadrature phase-relationship between ocean and atmosphere on intraseasonal timescales that has already been reported in other studies (Zheng, 2004; Rajendran and Kitoh, 2006; Kim et al., 2008; Maloney et al., 2008; Saha et al., 2010; Kim et al., 2010). The same diagnostic with either OSTIA or AVHRR SST shows a relatively distorted relationship (Fig. 7) that is visible in the first days of the MJO hindcasts forced by either of these SST products (Fig. 8). As the forecast lead time increases, the atmosphere seems to adapt to the SST fields to recover the expected quadrature. This pattern most probably reflects the initialization shock following the switch from ERAi SST (used to initialize the model) to OSTIA or AVHRR SST boundary conditions.

Difference of spatial patterns between SST products can be an additional source of loss of MJO forecast skill. Even smoothed by the interpolation from their original grid to the atmospheric one, the resulting SST fields are not as smooth as ERAi SST. Switching to higher frequency lower boundary conditions may generate air-sea interactions weakening the MJO signal in a low resolution atmosphere starting from an initial state produced using smooth ERAi SST. The Maritime Continent being a barrier to the MJO prediction, an initially weakened MJO signal will have difficulties to propagate over and past this barrier, as described in Fig. 6. A way to assess the impact of the switch of boundary conditions would be to produce an atmospheric reanalysis with either OSTIA or AVHRR SST forcings and perform again the MJO hindcasts using the new inital conditions.

Several studies (Zheng, 2004; Rajendran and Kitoh, 2006; Kim et al., 2008; Maloney et al., 2008; Saha et al., 2010; Kim et al., 2010) show that the ocean-atmosphere coupling improves the phase relationship between SST and convection (or precipitation) at intraseasonal timescale. Our coupled ex- periment provides an intense quadrature phase relationship between SST and convection (Fig. 8). The coupling provides a tighter ocean-atmosphere connection than in atmosphereonly mode and, more surprisingly, than in the reanalysis or the observations (Figs. 7 and 8). The MJO scores show a significant gain of skill compared to the forced experiment (Fig. 9), which coincides with the maintenance of the ocean-atmosphere quadrature phase relationship throughout the hindcasts. The extent to which the relative gain of MJO skill in the coupled experiment is linked to a phase relationship substantially stronger than the observed one and whether this is realistic or not need to be investigated in future works.

To conclude, this study shows that switching to SST boundary conditions that are different from the inital conditions has a sgnificant impact on the skill of MJO hindcasts. The degraded MJO scores obtained with the two GHRSST products tested here probably come from inconsistencies between ocean and atmosphere after the switch, leading to initial adjustment processes that will degrade the quality of the hindcasts. The phase relationship diagnostic gives insights into these adjustments and the pertubation of ocean-atmosphere coupled processes following the change of SST forcing. This diagnostic highlights how important realistic ocean-atmosphere interactions are in MJO hindcasts. This conclusion is reinforced when assessing the impact of a coupled system on such hindcasts. This study is however far from being exhaustive. For example, such MJO experiments could be repeated with other versions of the ECMWF model, other atmospheric models, at higher resolutions and over other periods, and could focus on other atmospheric patterns. Using more recent periods would also allow to test the impact of SST products derived from satellites using microwave sensors like the Advanced Microwave Scanning Radiometer (AMSR available from 2002, see http: //www.ncdc.noaa.gov/) or the Tropical Rainfall Mesasuring Mission Microwave Imager (TMI availble from 1997, see http://www.ssmi.com/). Such sensors should better handle the persistent cloud cover over the Tropics than infrared sensors and thus provide better SST products that would be worth testing in the context of MJO hindcasts.

Acknowledgements. Eric de Boisseson is supported by CNRSINSU and ECMWF. This is a contribution to the MyOcean project.

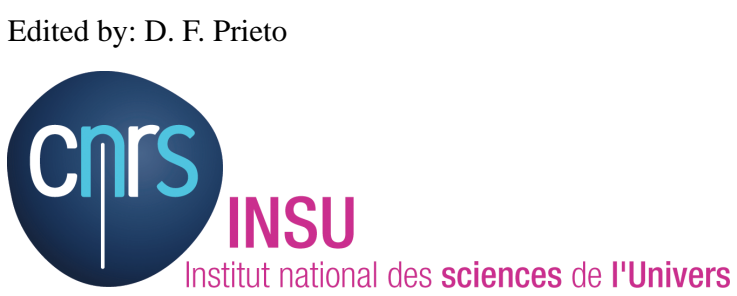

The publication of this article is financed by CNRS-INSU. 


\section{References}

Anderson, S. P., Weller, R. A., and Lukas, R. B.: Surface buoyancy forcing and the mixed layer of the western Pacific warm pool: observations and 1D model results, J. Climate, 9, 3056-3085, doi:10.1175/1520-0442(1996)009<3056:SBFATM>2.0.CO;2, 1996.

Cassou, C.: Intraseasonal interaction between the Madden-Julian Oscillation and the North Atlantic Oscillation, Nature, 455, 523527, 2008.

Dee, D. P., Uppala, S. M., Simmons, A. J., Berrisford, P., Poli, P., Kobayashi, S., Andrae, U., Balmaseda, M. A., Balsamo, G., Bauer, P., Bechtold, P., Beljaars, A. C. M., van de Berg, L., Bidlot, J., Bormann, N., Delsol, C., Dragani, R., Fuentes, M., Geer, A. J., Haimberger, L., Healy, S. B., Hersbach, H., Holm, E. V., Isaksen, L., Kallberg, P., Kohler, M., Matricardi, M., McNally, A. P., Monge-Sanz, B. M., Morcrette, J.-J., Park, B.-K., Peubey, C., de Rosnay, P., Tavolato, C., Thepaut, J.-N., and Vitart, F.: The ERA-Interim reanalysis: configuration and performance of the data assimilation system, Q. J. Roy. Meteorol. Soc., 137, 553597, 2011.

Donlon, C., Robinson, I., Casey, K., Vasquez, J., Armstrong, E., Gentemann, C., May, D., LeBorgne, P., Pioll, J., Barton, I., Beggs, H., Poulter, D. J. S., Merchant, C., Bingham, A., Heinz, S., Harris, A., Wick, G., Emery, B., Stuart-Menteth, A., Minnett, P., Evans, B., Llewellyn-Jones, D., Mutlow, C., Reynolds, R., Kawamura, H., and Rayner, N.: The Global Ocean Data Assimilation Experiment High-resolution Sea Surface Temperature Pilot, B. Am. Meteorol. Soc., 88, 1197-1213, 2007.

Donlon, C. J., Martin, M., Stark, J. D., Roberts-Jones, J., Fiedler, E., and Wimmer, W.: The Operational Sea Surface Temperature and Sea Ice analysis(OSTIA), Remote Sens. Environ., 116, 140-158, doi:10.1016/j.rse.2010.10.017, 2011.

Fiorino, M.: A multi-decadal daily sea surface temperature and sea ice concetration data set for the ERA-40 reanalysis, ERA-40 Project Report Series No 12, ECMWF: Reading, UK, 2004.

Gemmill, W., Katz, B., and Li, X.: Daily, Real-Time, Global Sea Surface Temperature - High Resolution Analysis: RTG SST HR, NCEP/EMC Office Note, pp. 39, 2007.

Hendon, H. H.: Air-sea interaction, in: Intraseasonal Variability in the Atmosphere-Ocean Climate System, edited by: Lau, W. K. M. and Waliser, D. E., Springer Praxis Books, 223-246, 2005.

Hendon, H. H. and Liebmann, B.: A composite study of onset of the Australian summer monsoon, J. Atmos. Sci., 47, 2227-2240, 1990.

Inness, P. M., Slingo, J. M., Guilyardi, E., and Cole, J.: Simulation of the Madden-Julian Oscillation in a Coupled General Circulation Model. Part II: The role of the basic state, J. Climate, 16, 365-382, 2003.

Kessler, K. S. and McPhaden, M.: Oceanic equatorial waves and the 1991-93 El Niño, J. Climate, 8, 1757-1774, 1995.

Kim, H. M., Hoyos, C. D., Webster, P. J., and Kang, I. S.: Sensitivity of MJO Simulation and Predictability to Sea Surface Temperature Variability, J. Climate, 21, 5304-5317, 2008.

Kim, H. M., Hoyos, C. D., Webster, P. J., and Kang, I. S.: Oceanatmosphere coupling and the boreal winter MJO, Clim. Dynam., 35, 771-784, doi:10.1007/s00382-009-0612-x, 2010.

Klingaman, N. P., Woolnough, S. J., Weller, H., and Slingo, J. M.: The Importance of High-Frequency Sea Surface Temperature Variability to the Intraseasonal Oscillation of Indian Monsoon Rainfall, J. Climate, 21, 6119-6140, doi:10.1175/2008JCLI2329.1, 2008.

Krishnamurti, T. N., Oosterhof, D. K., and Metha, A. V.: Air-sea interaction on the timescale of 30-50 days, J. Atmos. Sci., 45, 1304-1322, 1988.

Liebmann, B. and Smith, C. A.: Description of a Complete (Interpolated) Outgoing Longwave Radiation Dataset, B. Am. Meteorol. Soc., 77, 1275-1277, 1996.

Lin, J. L., Kiladis, G. N., Mapes, B. E., Weickmann, K. M., Sperber, K. R., Lin, W., Wheeler, M., Schubert, S. D., Del Genio, A., Donner, L. J., Emori, S., Gueremy, J.-F., Hourdain, F., Rasch, P. J., Roeckner, E., and Scinocca, J. F.: Tropical Intraseasonal Variability in 14 IPCC AR4 Climate Models Part I: Convective Signals, J. Climate, 19, 2665-2690, 2006.

Lin, H., Brunet, G., and Derome, J.: Forecast skill of the MaddenJulian Oscillation in two Canadian atmospheric models, Mon. Weather Rev., 136, 4130-4149, 2008.

Madec, G.: NEMO ocean engine, Tech. Rep. 27, Notes du pôle de Modélisation - Institut Pierre-Simon Laplace, 300 pp., 2008.

Maloney, E. D., Chelton, D. B., and Esbensen, S. K.: Subseasonal SST Variability in the Tropical Eastern North Pacific during Boreal Summer, J. Climate, 21, 4149-4167, doi:10.1175/2007JCLI1856.1, 2008.

Molteni, F., Stockdale, T., Balmaseda, M., Balsamo, G., Buizza, R., Ferranti, L., Magnusson, L., Mogensen, K., Palmer, T., and Vitart, F.: The new ECMWF seasonal forecast system (Sytem 4), ECMWF Tech. Memo. No 656, November 2011.

Murakami, T.: Cloudiness fluctuations during the summer monsoon, J. Meteor. Soc. Japan, 54, 175-181, 1976.

Rajendran, K. and Kitoh, A.: Modulation of Tropical Intraseasonal Oscillations by Ocean-Atmosphere Coupling, J. Climate, 19, 366-391 doi:10.1175/JCLI3638.1, 2006.

Rayner, N. A., Parker, D. E., Horton, E. B., Folland, C. K., Alexander, L. V., Rowell, D. P., Kent, E. C., and Kaplan, A.: Global analyses of sea surface temperature, sea ice, and night marine air temperature since the late nineteenth century, J. Geophys. Res., 108, 4407, doi:10.1029/2002JD002670, 2003.

Reichler, T. and Roads, J. O.: Long-range predictability in the tropics. part II: 30-60-day variability, J. Climate, 18, 634-650, doi:10.1175/JCLI-3295.1, 2005.

Reynolds, R. W., Rayner, N. A., Smith, T. M., Stokes, D. C., and Wang, W.: An Improved In Situ and Satellite SST Analysis for Climate, J. Climate, 15, 1609-1625, 2002.

Reynolds R. W., Smith, T. M., Liu, C., Chelton, D. B., Casey, K. S., and Schlax, M. G.: Daily High-Resolution-Blended Analyses for Sea Surface Temperature, J. Climate, 20, 5473-5496, doi:10.1175/2007JCLI1824.1, 2007.

Roberts-Jones J., Fiedler, E. K., and Martin, M. J.: Daily, Global, High-Resolution SST and Sea Ice Reanalysis for 19852007 Using the OSTIA System, J. Climate, 25, 6215-6232, doi:10.1175/JCLI-D-11-00648.1, 2012.

Saha, S., Moorthi, S., Pan, H.-L., Wu, X., Wang, J., Nadiga, S., Tripp, P., Kistler, R., Woollen, J., Behringer, D., Liu, H., Stokes, D., Grumbine, R., Gayno, G., Wang, J., Hou, Y.-T., Chuang, H.Y., Juang, H.-M. H., Sela, J., Iredell, M., Treadon, R., Kleist, D., Van Delst, P., Keyser, D., Derber, J., Ek, M., Meng, J., Wei, H., Yang, R., Lord, S., Van Den Dool, H., Kumar, A., Wang, W., Long, C., Chelliah, M., Xue, Y., Huang, B., Schemm, J.-K., Ebisuzaki, W., Lin, R., Xie, P., Chen, M., Zhou, S., Higgins, W., 
Zou, C.-Z., Liu, Q., Chen, Y., Han, Y., Cucurull, L., Reynolds, R. W., Rutledge, G., and Goldberg, M.: The NCEP climate forecast system reanalysis, B. Am. Meteorol. Soc., 91, 1015-1057, doi:10.1175/2010BAMS3001.1, 2010.

Shinoda, T., Hendon, H. H., and Glick, J.: Intraseasonal variability of surface fluxes and sea surface temperature in the tropical western Pacific and Indian oceans, J. Climate, 11, 1685-1702, doi:10.1175/1520-0442(1998)011<1685:IVOSFA > 2.0.CO;2, 1998.

Slingo, J. M., Sperber, K. R., Boyle, J. S., Ceron, J.-P., Dix, M., Dugas, B., Ebisuzaki, W., Fyfe, J., Gregory, D., Gueremy, J.F., Hack, J., Harzallah, A., Inness, P., Kitoh, A., Lau, W. K.M., McAvnaey, B., Madden, R., Matthews, A., Palmer, T. N., Park, C.-K., Randall, D., and Renno, N.: Intraseasonal oscillations in 15 atmospheric general circulation models: Results from an AMIP diagnostic subproject, Clim. Dynam., 12, 325-357, 1996.

Takaya, Y., Bidlot, J.-R., Beljaars, A. C. M., and Janssen, P. A. E. M.: Refinements to a prognostic scheme of skin sea surface temperature, J. Geophys. Res., 115, C06009, doi:10.1029/2009JC005985, 2010.

Vitart, F., Woolnough, S. J., Balmaseda, M. A., and Tompkins, A. M.: Monthly Forecast of the Madden-Julian Oscillation Using a Coupled GCM, Mon. Weather Rev., 135, 2700-2715, 2007.

Vitart, F. and Molteni, F.: Simulation of the Madden-Julian Oscillation and its teleconnections in the ECMWF forecast system, Q. J. Roy. Meteorol. Soc., 136, 842-855, April 2010.
Wheeler, M. C. and Hendon, H. H.: An All-Season Real-Time Multivariate MJO Index: Development of an Index for Monitoring and Prediction, Mon. Weather Rev., 132, 1917-1932, 2004.

Woolnough, S. J., Slingo, J. M., and Hoskins, B. J.: The Relationship between Convection and Sea Surface Temperature on Intraseasonal Timescales, J. Climate, 13, 2086-2104, doi:10.1175/1520-0442(2000)013<2086:TRBCAS > 2.0.CO;2, 2000.

Woolnough, S. J., Vitart, F., and Balmaseda, M. A.: The role of the ocean in the Madden-Julian Oscillation: Implications for MJO prediction, Q. J. Roy. Meteorol. Soc., 133, 117-128, 2007.

Yasunari, T.: Cloudiness fluctuations associated with the Northern Hemisphere summer monsoon, J. Meteor. Soc. Japan, 57, 225242, 1979.

Zeng, X. and Beljaars, A.: A prognostic scheme of sea surface skin temperature for modeling and data assimilation, Geophys. Res. Lett., 32, L14605, doi:10.1029/2005GL023030, 2005.

Zhang, C.: Madden-Julian Oscillation, Rev. Geophys., 43, RG2003, doi:10.1029/2004RG000158, 2005.

Zheng, Y., Waliser, D. E., Stern, W. F., and Jones, C.: The Role of Coupled Sea Surface Temperatures in the Simulation of the Tropical Intraseasonal Oscillation, J. Climate, 17, 4109-4134, doi:10.1175/JCLI3202.1, 2004. 